\title{
РИСКИ ОБОРОННЫХ ПРЕДПРИЯТИЙ И ИХ ПРОЯВЛЕНИЕ НА РАЗЛИЧНЫХ ЭТАПАХ ЖИЗНЕННОГО ЦИКЛА ИЗДЕЛИЙ
}

\section{RISKS OF DEFENSE ENTERPRISES AND THEIR MANIFESTATION AT DIFFERENT STAGES OF THE PRODUCT LIFE CYCLE}

A. Kravtsov

A. Kryukov

Summary. The concept of the life cycle of an industrial product is considered and its main stages are shown. A study of the risks inherent in defense enterprises at various stages of the product life cycle has been carried out. The research of the scientific category of risk and the concept of uncertainty, inseparable from it, has been carried out. It is shown that experimental and designed works as a stage of the life cycle faces the greatest number of risks. The classification of risks is presented and it is shown that the most significant risks are production and personnel (management) risks. The necessity of assessing production risks of experimental and designed works has been substantiated.

Keywords: defense enterprises, production risks, uncertainty, risk assessment, classification of risks.

\author{
Кравчов Андрей Андреевич \\ K.т.н, дочент, АО «Концерн ВКО «Алмаз-Антей» \\ a.kravcov@almaz-antey.ru \\ Крюков Алексей Анатольевич \\ АО «Концерн ВКО «Алмаз-Антей» \\ alexeykryukov@yandex.ru
}

Аннотация. Рассмотрено понятие жизненного цикла изделия промышленного назначения и основные его этапы. Проведено исследование рисков, присущих оборонным предприятиям на различных этапах жизненного цикла изделий. Проведено исследование научной категории риска и неотделимого от него понятия неопределенности. Показано, что ОКР как этап жизненного цикла, сталкивается с наибольшим количеством рисков. Представлена классификация рисков и обосновано, что наиболее значимыми рисками являются производственные и кадровые (управленческие) риски. Обоснована необходимость оценки производственных рисков ОКР.

Ключевые слова: оборонные предприятия, производственные риски, неопределенность, оценка риска, классификация рисков.
Д еятельность по созданию и эксплуатации В и ВТ сопряжена со множеством проблем, оказывающих влияние на заключение и исполнение контрактов, а также на создание и поставку В и ВТ. Среди основных проблем следует назвать геополитическую ситуацию, сложившуюся в результате действующих против Российской Федерации санкций по инициативе EC, США и других стран, а также осложнения в связи с глобальной пандемией короновируса. Это нарушило ранее отлаженные деловые контакты, сократило объем заказов и инвестиций в ОПК, ограничило закупки материалов и комплектующих. На фоне внешнеэкономических санкций негативный эффект на финансирование ОПК оказывает общее ослабление национальной экономики. Это проявляется в сокращении бюджетных расходов на ОПК, снижению платежеспособности и финансовой устойчивости оборонных предприятий.

Доходы оборонных предприятий во многом ограничены ГОЗ, поэтому повышение прибыли предприятия ОПК возможно, как правило, лишь при снижении затрат, хотя действующая система ценообразования этого не гарантирует. Актуальной остается кадровая проблема, которая заключается в нехватке высококва- лифицированных кадров и потере конкурентоспособности предприятий ОПК на рынке труда [1].

Создание и эксплуатация ВВТ осуществляется в рамках жизненного цикла продукции, под которым подразумевается совокупность взаимосвязанных процессов изменения состояния продукции при ее создании, использовании (эксплуатации) и ликвидации (с избавлением от отходов путем их утилизации и/или удаления) [2].

Жизненный цикл продукции можно рассматривать как «проект». Согласно определению ГОСТ Р ИСО 90002015, жизненный цикл является процессом изменения состояний продукции. В зависимости от набора таких «состояний» жизненный цикл состоит из стадий:

- формирование и обоснование концепции проекта и его идеи;

- разработка технического предложения;

- разработка технического задания (далее - Т3);

- проведение ОКР (при необходимости НИОКР, OTP);

- серийное производство и испытания образцов;

- модернизация продукции; 
- использование (эксплуатация) разработанных образцов;

- сервисное обслуживание и ремонт;

- ликвидация.

В нормативной документации содержатся требования к каждой стадий жизненного цикла и их детализация. Стадии жизненного цикла могут быть как строго последовательными, так и проходить одновременно. Ключевыми стадиями жизненного цикла продукции являются НИР и ОКР, поскольку именно на этих стадиях оценивается результативность проектов, достижимость поставленных целей и задач проекта, закладываются эксплуатационные характеристики будущих образцов В и ВТ, формируются конкурентные преимущества конструируемых образцов [3].

Деятельность предприятий ОПК при создании средств вооружения в рамках государственного оборонного заказа сопряжена с неопределенностью и повышенным уровнем риска на всех этапах жизненного цикла изделий. Выявленные в ходе анализа проблемы являются следствием отсутствия эффективной системы оценки рисков оборонных предприятий, прежде всего на этапе ОКР [4].

Обратимся к научной литературе для анализа существующих подходов к трактовке категории риска и неотделимого от него понятия неопределенности.

Авторы А.Т. Шилкина, А.Г. Савкин рассматривают понятие «риск» как характеристику управления в условиях неопределенности и недостаточности информации при выборе альтернативы. Риск определяют как потенциально существующую вероятность потери ресурсов или неполучения доходов в результате принятия решения [5]. Критерии выбора альтернативного решения и его результативность оцениваются на основе вероятности возникновения и меры влияния негативных факторов внешней среды бизнеса [5]. По мнению авторов, размер потерь в условиях неопределенности является ценой риска, а величина успеха (дохода или другой выгоды) - платой за риск.

Рассмотрим определение категории риска, содержащееся в нормативных документах в управленческой практике. Согласно ГОСТ Р ИСО 31000-2010 - «Менеджмент риска. Принципы и руководство», риск - это влияние неопределенности на цели. В ГОСТ Р 51897-2002 «Менеджмент риска. Термины и определения» говорится, что риск - сочетание вероятности события и его последствий, результатом которых является отклонение заданных (фактических) параметров процесса или проекта от запланированных.
Принятие управленческих решений при правлении ОКР и/или предприятием является непрерывным процессом, реализуемым в условиях неопределенности и основанным на объективной, полной, достоверной, своевременной и оперативной информационно-аналитической базе. Неопределенность порождает возникновение на практике ситуаций с непредсказуемым исходом, требуя принятия решений с помощью экономико-математических моделей двух типов [4]:

- ситуация принятия решения в условиях риска, когда существует множество вероятных исходов в результате каждого предпринятого действия, вероятность которых может быть вычислена или экспертно оценена;

- ситуация принятия решения в условиях неопределенности, когда имеется множество вероятных исходов для каждого предпринятого действия, вероятность которых не может быть вычислена или оценена.

Принятие решения в условиях риска происходит в условиях неизвестной вероятности появления рисковых ситуаций и их влияния на конечный результат ОКР. Вероятность оценивается различными методами математической статистики, теории вероятностей. Поэтому идентификация, оценка и мониторинг рисков является приоритетной задачей для принятия управленческих решений.

Научный подход к определению риска как экономической категории рассматривается в рамках двух концепций. Авторы Д. Милль, Н. Сениор считают, что плата за риск является частью получаемых выгод. Риск оценивается как ущерб (математическое ожидание потерь) в результате принимаемого управленческого решения. По мнению А. Маршалла, А. Пигу, руководитель принимает решения в условиях неопределенности, оценивая предполагаемые выгоды и вероятность их получения при различных сценариях. Д. Кейнс под «потерями от риска» понимал отклонение фактического дохода от ожидаемого [6]. Доход невозможен без неопределенности и является ее следствием, при ее отсутствии он равен 0.

Рассмотрим взаимосвязь понятий неопределенности и риска. Ф. Найт указывает кардинальные отличия данных понятии, поскольку риск можно оценить количественно, в отличие от неопределенности: «риск это «оцениваемая неопределенность» [7].

Аналогичное мнение высказывают Т. Бачкаи и Д. Месена, трактуя ситуации риска как ситуации с оценкой вероятности появляющихся событий. Отклонение от цели, достижение которой требует принятия решений, является проявлением риска. Риск в таком случае 
трактуется как уровень неопределенности ожидаемого результата, или как вероятность неудачи или наоборот, выигрыша от принятого решения, выбора альтернативы среди возможных [8].

В.М. Гранатуров определяет условия появления ситуации риска, определяющие его сущность:

- необходимость принятия управленческого решения, выбора альтернативы из нескольких возможных вариантов;

- отклонение от цели проекта, что требует принятия решения и выбора альтернатив;

- численная оценка вероятности различных исходов принятия решения и выбора альтернатив;

- неопределенность исхода конкретной ситуации, что отражает вероятность достижения или недостижения поставленной цели;

- вероятность недополучения выгод или потерь ресурсов при реализации выбранной в условиях неопределенности альтернативы.

Однозначного и общепринятого подхода к определению риска в законодательстве или научной литературе сегодня не существует. Это обусловлено многогранностью и многоаспектностью риска, разными подходами к его пониманию в различных сферах науки и практики, где риск трактуется по-разному [9].

Другие авторы под риском понимают ситуацию неопределенности как неотъемлемой составляющей принятия решений, которая может привести как к получению выгод, так и потерь вследствие принимаемого решения. Неопределенность связана с событиями, которые приводят к возможным потерям или выгодам вследствие принимаемых решений для достижения целей и задач ОКР, и характеризуется вероятностью появления данных событий, которые могут быть как благоприятными, так и неблагоприятными [10].

В работе [6] риском считается вероятность неблагоприятного результата, потерь ресурсов, недополучения выгод, недостижения целей и задач проекта, нанесения ущерба населению, имуществу и окружающей среде.

Г.В. Чернова, А.А. Кудрявцев определяют риск как опасность возникновения ущерба, угрозу появления неких событий, которые повлекут за собой убытки и потери; угроза превышения фактических потерь над ожидаемыми, или получения более низких доходов по сравнению с планируемыми в ходе предпринимательской деятельности или реализации проекта [11].

B.А. Абчук считает риск ситуативной характеристикой, которая отражает неопределенность исхода проекта или замысла и вероятность неблагоприятного результата при неудаче. Риск определяется также как следствие действия либо бездействия, в результате которых возникает неопределенный исход с позитивным или негативным влиянием на результат деятельности. Принятие решения - это обоснование и реализация мероприятий по достижению поставленных целей и преодоление неопределенности путем выбора альтернативы с количественной и качественной оценкой вероятности достижения или недостижения ожидаемого результата, или отклонения от него [12]. Автором подчеркивается важность оценки рисков для принятия решений и достижения целей проекта.

В.В. Ковалёв считает, что риск - оценка степени достижимости и реализуемости принимаемого управленческого решения и возможных при этом потерь [13].

В научных трудах П.Г. Грабового риск - это отдельное случайное событие или множество взаимосвязанных и взаимозависимых случайных событий, наносящих ущерб проекту [14]. Аналогично другой автор понимает под риском событие, которое угрожает успешному достижению поставленных целей и задач проекта. Это вероятность возникновения случайного события на протяжении жизненного цикла изделия или проекта [15].

Риск трактуется как вероятность отклонения от поставленных целей и задач, ожидаемых результатов проекта, и оценивается до начала проектных работ. Под риском также понимается вероятность отклонений индикаторов эффективности от нормативных или эталонных значений; вероятность ненаступления прогнозируемых событий [16].

Аналогично высказанным ранее позициям авторов, А.П. Альгин считает, что риск - это возможность отклонения от поставленной цели, достижение которой требует принятия решения [17]. Г.И. Храмов трактует риск как совокупность управленческих мероприятий и действий, ставящий под угрозу достижение поставленных целей и задач проекта по причине неопределенности [18].

На основе проведенного анализа научных подходов к трактовке риска можно сделать вывод, что сущность риска проявляется в сравнении первоначальных целей и задач с конечными ожидаемыми результатами ОКР, при этом мера несовпадения между ними и есть мерой риска. При совпадении планируемых результатов ОКР с фактическими риск отсутствует, то есть он равен 0.

Согласно большинству исследований теоретиков и практиков, риск зависит от отрасли и сферы деятельности. При этом риск не следует воспринимать как 


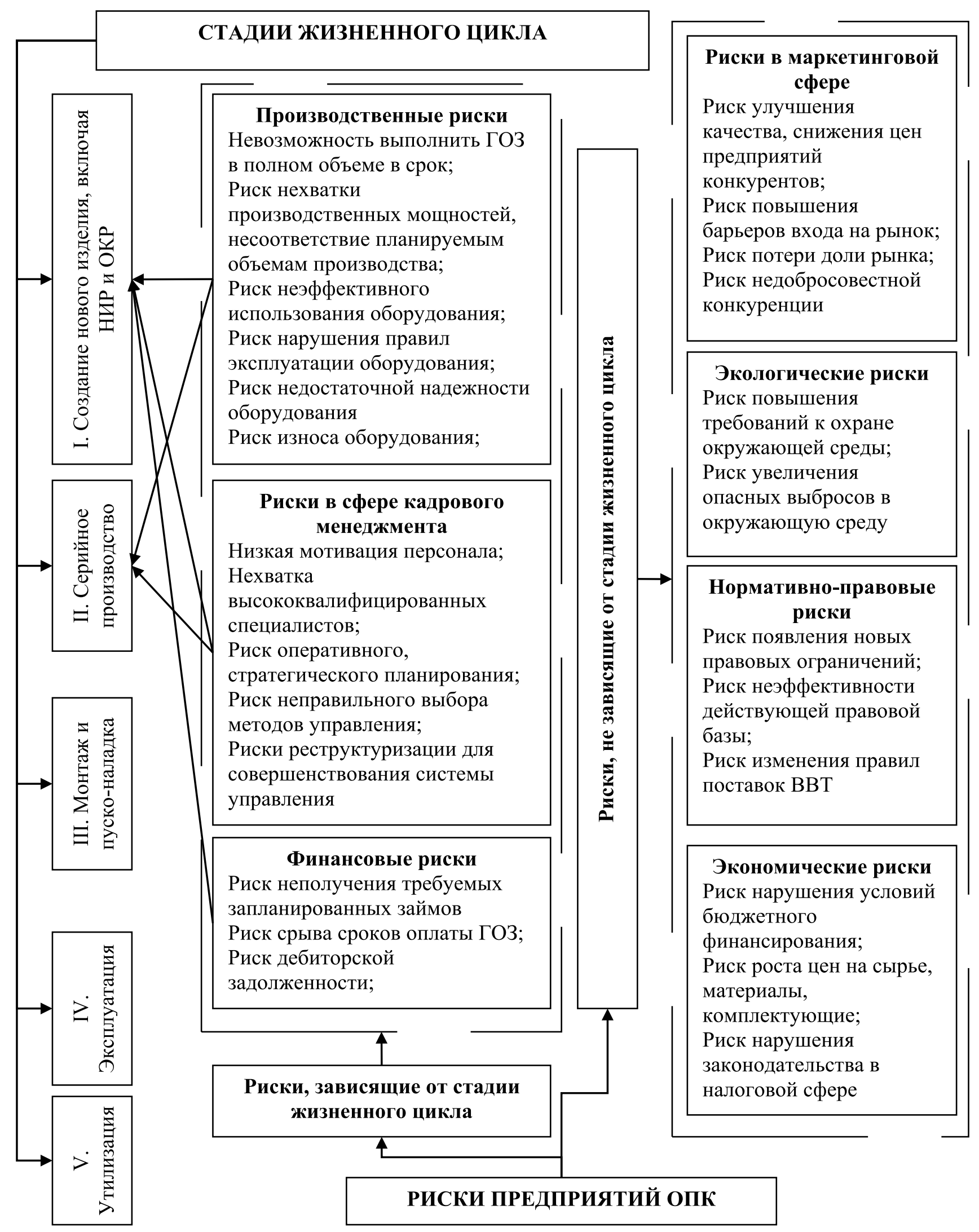

Рис. 1. Классификация рисков предприятия ОПК в зависимости от стадии жизненного цикла Источник: составлено автором на основе [1], [18] 
опасность либо неблагоприятное событие. Он также может стать источником новых возможностей и получения выгод, а также новым выгодным направлением деятельности. Поэтому следует фокусироваться не на снижении риска, а на получении наилучшего результата по ОКР при приемлемом уровне риска.

Таким образом, риск неотделим от проектной деятельности, инноваций и новых технологий, создания новых объектов с улучшенными свойствами и других мероприятий с неопределенным результатом. Фактические результаты проекта в большинстве случаев отклоняются от плановых. Размер отклонения является случайной величиной и зависит от уровня риска.

Риск проявляется в наличии или отсутствии случайного события, которое создает ситуацию риска, вероятность которой заранее известна или может быть оценена. Риск оценивается как отклонение фактического исхода, результата или оценочного индикатора от прогнозируемых вследствие появления одного или нескольких рисковых событий.

Риск сопутствует принимаемым решениям и существует объективно, независимо от управленческой деятельности. Он вызван в большинстве случаев внешними и внутренними факторами среды. При этом восприятие риска и уровня его влияния на конечный результат ОКР субъективны и зависят от специфики конкретной ОКР, а также от отношения к риску лиц, принимающих решение и осуществляющих его оценку и мониторинг.
Присутствующие в деятельности оборонных предприятий риски многообразны и специфичны для ОПК, но при этом индивидуальны для конкретного предприятия. А.Т. Шилкина, О.Е. Варакина выделяют внешние и внутренние риски предприятий ОПК. При этом ко внутренним рискам относятся производственные, финансовые, маркетинговые, кадровые риски. К внешним рискам авторы относят экономические, нормативно-правовые, экологические, конкурентные риски.

Основываясь на представленных в научной литературе классификациях рисков предприятий ОПК[1], на рис. 1 представим классификацию рисков предприятий ОПК в соответствии со стадиями жизненного цикла продукции с точки зрения их оценки и управления.

Как можно подытожить, приоритетными рисками в деятельности предприятий ОПК являются именно производственные и кадровые (управленческие) риски, которые проявляются на начальных стадиях жизненного цикла продукции, оказывая влияние на организацию процесса производства В и ВТ. Предлагаемая классификация позволит структурировать и систематизировать возникающие проблемы, разрабатывать методические рекомендации по оценке рисков оборонных предприятий, проводить их мониторинг, анализировать рисковые ситуации и обосновать выбор методов управления рисками с учетом источников их возникновения и стадий жизненного цикла продукции.

\section{ЛИТЕРАТУРА}

1. Шилкина, А.Т. Особенности управления рисками на предприятиях оборонно-промышленного комплекса [Электронный ресурс] / А.Т. Шилкина, 0.Е. Варакина // Региональная экономика: теория и практика. — 2018. — Т. 16, № 3.— C. 472-483. — Режим доступа: https://doi.org/10.24891/re.16.3.472

2. ГОСТ Р ИСО 9000-2015 «Система менеджмента качества. Основные положения и словарь». [Электронный ресурс].— Режим доступа: https:// meganorm.ru/Data2/1/4293759/4293759339.pdf

3. Куркова, 0.П. Организация и планирование научно-технических исследований и разработок: монография [Электронный ресурс] / 0.П. Куркова.СПб.: Наукоемкие технологии, 2018. - 245 с.—Режим доступа: http://publishing.intelgr.com/archive/research-organization.pdf.

4. Дубров, А.М. Моделирование рисковых ситуаций в экономике и бизнесе: Учеб. пособие / А.М. Дубров, Б.А. Лагоша.- М.: Финансы и статистика, 2001. - 224 C.

5. Шилкина, А.Т. Управление рисками в системе менеджмента качества промышленного предприятия: региональный аспект [Электронный ресурс] / А.Т. Шилкина, А.Г. Савкин // Фундаментальные исследования.— 2015.— № 7-4.—C. 857-862.— Режим доступа: http://fundamental-research.ru/ ru/article/view?id=38836 (дата обращения: 12.09.2020).

6. Бернстайн, Л.А. Против богов. Укрощение риска / Л.А. Бернстайн; пер. с англ. - М.: Олимп-Бизнес, 2000. -400 c.

7. Найт, Ф.Х. Риск, неопределенность и прибыль / Ф.Х. Найт; пер. с англ.—М.: Дело, 2003.— 360 с.

8. Бачкаи, Т. Хозяйственный риск и методы его измерения / Т. Бачкаи [и др.]; пер. с венгер. - М.: Экономика, 1979. - 184 с.

9. Буянов, В.П. Рискология (управление рисками) / В.П. Буянов, К.А. Кирсанов, Л.М. Михайлов.— М.: Экзамен, 2003. - 384 С.

10. Станиславчик, Е.Н. Риск-менеджмент на предприятии. Теория и практика / Е.Н. Станиславчик. — М.: 0сь-89, 2002. - 80 с.

11. Чернова, Г.В. Управление рисками / Г.В. Чернова, А.А. Кудрявцев. - М.: Велби: Проспект, 2003. - 160 с.

12. Абчук, В.А. Риски в бизнесе, менеджменте и маркетинге / В.А. Абчук.-СПб.: Изд-во Михайлова В.А., 2006. - 480 с.

13. Ковалёв, В.В. Введение в финансовый менеджмент / В.В. Ковалёв.—М.: ФиС, 2004. - 768 с.

14. Риски в современном бизнесе / П. Г Грабовый [и др.]. — М.: АЛАНС, 1994. — 286 с. 
15. Хохлов, Н.В. Управление риском / Н.В. Хохлов. М.: ЮНИТИ-ДАНА, 2001. - 239 с.

16. Рогов, М.А. Риск-менеджмент / М.А. Рогов.-М.: ФиС, 2001.- 120 с.

17. Альгин, А.П. Риск и его роль в общественной жизни / А.П. Альгин.- М.: Мысль, 1989. - 187 с.

18. Колесов, К.И. Анализ рисков предприятий оборонно-промышленного комплекса при стратегическом планировании / К.И. Колесов, А.Ф. Плеханова, А.А. Иванов, Н.Д. Иванова // Фундаментальные исследования. — 2014. — № 8(3)._ C. 671-676. — Режим доступа: https://fundamentalresearch.ru/ ru/article/view?id=34613

○ Кравцов Андрей Андреевич ( a.kravcov@almaz-antey.ru), Крюков Алексей Анатольевич ( alexeykryukov@yandex.ru ). Журнал «Современная наука: актуальные проблемы теории и практики»

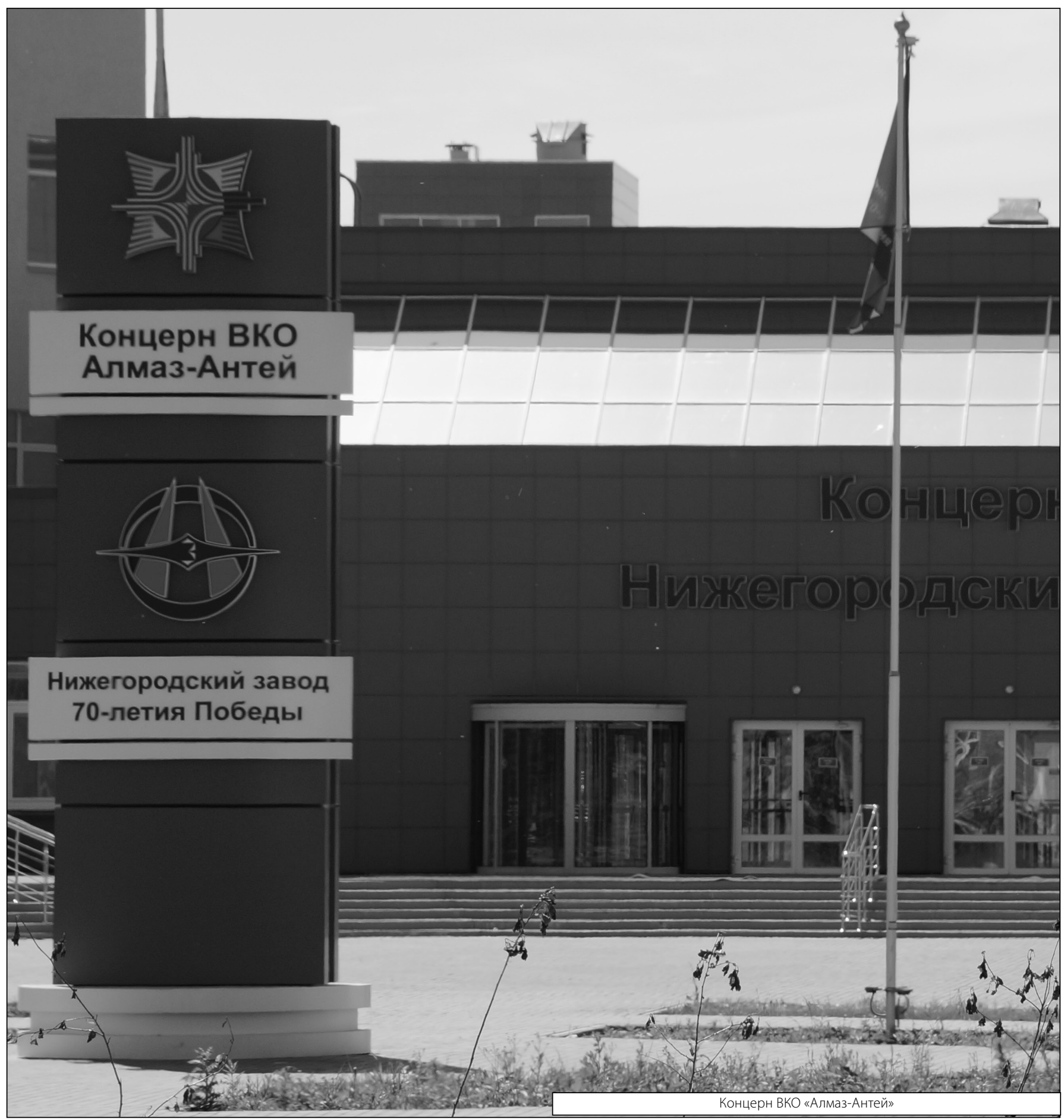

